\title{
Critérios pedagógicos, ambiente educacional, programa curricular e os aspectos didáticos: critérios relevantes na avaliação de softwares educacionais
}

\author{
Cristini Graebin, aluna do curso de Especialização em Mídias na Educação pela \\ Universidade Federal de Santa Maria, cristinigraebin@gmail.com
}

Resumo. Este artigo é fruto de um trabalho de pesquisa sobre critérios de avaliação de softwares educacionais. A partir de observações de diferentes realidades de uso dos softwares nos laboratórios de informática nas escolas foi possível verificar a necessidade de ter clareza sobre os critérios que devem ser observados na avaliação de softwares educacionais por professores.

Através do estudo dos autores (SANCHO, CAMPOS, GIRAFFA, OLIVEIRA) e da pesquisa realizada teve-se clareza sobre a importância de conhecer as várias listas de avaliação criadas e de combiná-las de maneira que as limitações que cada uma apresenta possam ser compensadas pelas vantagens das outras. Desta forma, essa pesquisa focou-se nos critérios pedagógicos relacionados ao ambiente educacional e seu programa curricular assim como os aspectos didáticos utilizados nas práticas vivenciadas nos laboratórios de informática municipais de Lajeado no estado do Rio Grande do Sul. Como resultado, verificou-se que os professores têm como principal foco de atenção os critérios pedagógicos, ou seja, a escolha do software a ser adotado está diretamente ligada aos objetivos que o educador deseja alcançar.

Palavras-chave: software educacional, critérios pedagógicos, ambiente educacional, programa curricular, aspectos didáticos

\section{Criteria educational, environmental education, curriculum and didactic aspects: relevant criteria in the evaluation of educational software}

\begin{abstract}
This paper is the result of research work on evaluation criteria for educational software. From observations of different situations of use of software in computer labs in schools was possible to verify the need for clarity on the criteria that must be observed the evaluation of educational software for teachers. Through the study of authors (SANCHO, CAMPOS, GIRAFFA, OLIVEIRA) and the research done has been clear about the importance of knowing the various lists of evaluation created and combine them so that the constraints that each of displays can be offset by other benefits. This research focused on the educational criteria related to environmental education and its curriculum and textbooks used in the issues experienced in practice computer laboratories in municipal Lajeado in the state of Rio Grande do Sul. As a result, it was found that teachers have a principal focus of attention the educational criteria, ie, the choice of software to be adopted is directly linked to the objectives that the teacher wishes to achieve
\end{abstract}

Keywords: educational software, criteria teaching, educational environment, curriculum, didactic aspects

\section{Introdução}

O uso do computador na educação hoje é inevitável. Como afirma Perrenoud (2000), a escola não pode ignorar o que se passa no mundo. Ora, as novas tecnologias da informação e da comunicação transformam espetacularmente não só nossas maneiras de comunicar, mas também de trabalhar, de decidir, de pensar.

A utilização de softwares para apoio ao processo de aprendizagem dos alunos é cada dia mais difundido nas escolas que implantaram laboratórios de informática. No entanto, a simples presença do computador com ferramentas/softwares educacionais na escola não significa uma melhoria na sua qualidade. Esta depende de vários fatores, entre elas, a qualidade do software.

A qualidade do software deve ser verificada através de uma criteriosa avaliação que analise os diversos aspectos, observando a visão da Engenharia de Software e também 
aspectos próprios de um software educacional, como por exemplo, a aplicação de teorias de aprendizagem.

O objetivo deste artigo é mostrar a pesquisa que foi realizada no sentido de criar critérios para avaliar o software educacional (SE) que sejam utilizados nas escolas que possuem laboratório de informática da rede municipal de Lajeado, por este motivo buscamos também conhecer as normas de qualidade e as expectativas dos professores destas escolas.

Percebeu-se que as necessidades e interesses da escola sempre devem ser a meta principal da equipe que irá avaliar o software educacional, porque não adianta ter qualidade, se não está de acordo com as concepções pedagógicas e a realidade da escola.

Por este motivo, há passos essenciais para selecionar e criar outros critérios de avaliação adequados a uma determinada realidade, estes passos são conhecer (1) os usos possíveis da informática na Educação e seus recursos, (2) visão da Engenharia de Software assim como os aspectos próprios de um software educacional, (3) listas de avaliação criadas por pesquisadores e sua epistemologia, (4) a realidade na qual será aplicada, ouvir seus atores (coordenadores pedagógicos e professores) e readequá-las para que dêem conta das expectativas e objetivos a serem alcançados pelo grupo.

\section{Teorias de aprendizagem e projeto político pedagógico como base para o trabalho com os softwares educacionais}

O projeto político-pedagógico é um instrumento que auxilia na organização do trabalho pedagógico. Seu objetivo é manter um processo de permanente reflexão e discussão da ação da escola, na busca constante de alternativas viáveis à efetivação de sua função educativa. Ele constitui um processo democrático de decisões, envolvendo todos os segmentos da comunidade escolar e preocupando-se em instaurar uma forma de organização do trabalho pedagógico que supere conflitos, elimine relações competitivas e autoritárias. Portanto, define os objetivos e o rumo que a escola irá percorrer para realizar sua função na formação do cidadão, respeitando a legislação vigente no país.

O projeto político-pedagógico é uma reflexão do professor sobre suas concepções teóricas que refletem na sua prática em sala de aula. Ele envolve as intenções e concepções de educação do educador, seu conhecimento a respeito dos conteúdos que pretende desenvolver, seus objetivos pedagógicos, o entendimento da realidade na qual atua, considerando as necessidades e expectativas de seus alunos, a estrutura escolar que o mantém e as novas tecnologias. O projeto político-pedagógico é a base para a escolha dos softwares educacionais. De acordo com Valente (1999, p. 114), a sobrevivência de muitos SE, mesmo daqueles de reconhecida qualidade, dependerá da existência de um projeto político-pedagógico que oriente suas aplicações.

A evolução tecnológica e a implantação de computadores nas escolas fez necessária a reflexão sobre a nova realidade e sua influência na escola, refletindo diretamente na elaboração do projeto político-pedagógico que é um momento muito importante que desafia a comunidade escolar a repensar as práticas pedagógicas mediadas pelas novas tecnologias. 
Para Oliveira (2001, p 90), o software educativo é uma ferramenta que deve estar integrada ao projeto pedagógico da escola como um dos recursos didáticos disponibilizados para o professor no seu papel de mediador do processo de ensinoaprendizagem.

O Projeto Pedagógico organiza o trabalho pedagógico sempre partindo do que se conhece e incorporando novas informações. Por este motivo é formado por dois eixos: o da abrangência e o do aprofundamento. O eixo da abrangência verá o todo, as relações entre os conhecimentos. O eixo do aprofundamento fará um recorte do todo e poderá examinar cuidadosamente as particularidades de um conhecimento. De acordo com Valente (1999) "a interdependência destes eixos é fundamental para a seleção do software, considerando suas contribuições para o seu papel no processo educativo a fim de criar situações significativas de aprendizagem".

O Projeto Pedagógico é a identidade da escola que é construído coletivamente, por todos os segmentos da vida escolar, sendo democrático, abrangente e flexível.

A avaliação do software educacional é complexa, pois é necessário que seja respeitado o projeto político-pedagógico da escola, os critérios de qualidade, as normas técnicas, a finalidade didática, as características de interface, o custo, a adaptação ao usuário, entre outros critérios.

\section{Da Engenharia de software ao software educacional}

Segundo Pressman (1995), uma primeira definição de Engenharia de Software (ES) foi proposta por Fritz Bauer na primeira grande conferência [NAU69] dedicada ao assunto: o estabelecimento e uso de sólidos princípios de engenharia para que se possa obter economicamente um software que seja confiável e que funcione eficientemente em máquinas reais.

Para a construção de softwares de qualidade, uma série de etapas precisa ser seguida. A Engenharia de Software, de acordo com Pressman (1995, p.31), "abrange um conjunto de três elementos fundamentais - métodos, ferramentas e procedimentos - que possibilita ao gerente o controle do processo de desenvolvimento do software e oferece ao profissional uma base para a construção de softwares de alta qualidade produtivamente".

Pressman (1995), argumenta que os métodos de ES proporcionam o "como fazer" para construir o software, as ferramentas, o apoio automatizado ou semi-automatizado aos métodos e os procedimentos formam o elo de ligação que mantém juntos os métodos e as ferramentas e possibilita o desenvolvimento racional e oportuno de um software de qualidade. O principal objetivo da ES é criar um software de qualidade que atinja os objetivos propostos pelo consumidor. A busca da competitividade mundial das indústrias e a necessidade em atingir padrões internacionais de qualidade, fizeram com que surgisse a preocupação com a qualidade do software.

Segundo Rocha (2001, p. 126), qualidade é a totalidade de características de um produto ou serviço que lhe confere a capacidade de satisfazer as necessidades implícitas de seus usuários. Um software para ter qualidade deve atender o usuário e isto será percebido de maneiras diferentes, de acordo com o interesse e as concepções teóricas de cada um. 
Portanto, um software educacional de qualidade deve garantir a autonomia, cooperação, criatividade, pensamento crítico, descoberta e construção de conhecimento do aluno.

O software deve satisfazer as necessidades do usuário, respeitando seus interesses. Quando se trata de um software educacional (SE) o processo fica mais complexo. A qualidade de um SE, além da parte técnica que as normas abordam satisfatoriamente, também há a necessidade de observar as concepções pedagógicas.

Avaliar a qualidade de um software educacional se torna uma questão complexa, pois envolve muitos aspectos inter-relacionados, envolvendo diversas áreas do conhecimento. É necessário observar os aspectos pedagógicos, técnicos, operacionais e relacionados a interface do produto. Para englobar todos estes aspectos, vários profissionais devem se envolver, formando uma equipe multidisciplinar. Os aspectos abordam conhecimentos das áreas de Ergonomia de Interface Homem Computador (IHC), Ergonomia Cognitiva, Engenharia de Software, Pedagogia, Psicologia e áreas especificas que envolvem o conteúdo abordado.

Pensar na qualidade em software educacional é pensar, paralelamente, as questões de tecnologia, em Engenharia de Software, em Educação, em Psicologia, em Ciência Cognitiva. Para a elaboração de um software educacional de qualidade, entre outros profissionais, deve-se contar com uma equipe multidisciplinar envolvendo profissionais de informática, comunicação, professores de conteúdo, de didática e alunos. Cada um destes profissionais, em suas respectivas áreas, inclusive o aluno, possui seus próprios critérios de qualidade, o que exige, sobretudo, respeito mútuo entre uma e outra categoria. (Campos, 2001)

Todo recurso utilizado em sala de aula deve ser analisado, pelos profissionais citados e pelo professor que ao avaliar a qualidade do SE, deve observar se favorece a aprendizagem dos alunos. Rocha (2001, p.125) afirma que no desenvolvimento de software educacional se começa a observar e contemplar as características da educação que contribuam para a formação global do aluno que necessita aprender a aprender e aprender a pensar para melhor intervir, inovar e questionar, trabalhando assim com as funções da cognição.

Valente (1999) enfatiza que um software só pode ser tido como bom ou ruim dependendo do contexto e do modo como ele será utilizado. Portanto, para ser capaz de qualificar um software é necessário ter muito clara a abordagem educacional a partir da qual ele será utilizado e qual o papel do computador nesse contexto, por este motivo os profissionais que desenvolvem e avaliam o SE precisam conhecê-la. Para identificar a proposta da escola, é necessário analisar o seu Projeto Político Pedagógico, no qual deixa clara a sua concepção de educação.

\section{Softwares educacionais (definição, critérios de qualidade e avaliação)}

Software educacional são programas de computador que foram projetados com um objetivo educacional, para auxiliar professor e aluno no processo de aprendizagem. No entanto, de acordo com Giraffa (1999), todo o programa pode ser considerado educacional desde que utilize uma metodologia que o contextualize no processo ensinoaprendizagem. Este conceito é bastante amplo e faz com que qualquer programa seja considerado educacional. Portanto, no momento que o professor utilizar um software com fins de ensino-aprendizagem, ele será considerado um Software Educacional. 
Pode-se citar como exemplos, os editores de textos e as planilhas de cálculos, que foram produzidos para o mercado de trabalho, mas são utilizados como ferramenta educacional nas escolas.

Segundo Oliveira (2001), as características de um SE são as seguintes:

- definição e presença de uma fundamentação pedagógica que permeie todo o seu desenvolvimento;

- finalidade didática, por levar o aluno/usuário a "construir" conhecimento relacionado com seu currículo escolar;

- interação entre aluno/usuário e programa, mediada pelo professor;

- facilidade de uso, uma vez que não se devem exigir do aluno conhecimentos computacionais prévios, mas permitir que qualquer usuário, mesmo que em primeiro contato com a máquina, seja capaz de desenvolver suas atividades;

- atualização quanto ao estado da arte.

Uma das características citadas é a presença de uma fundamentação pedagógica que permeie todo o desenvolvimento e que define a forma de interação do SE com o professor e aluno. É essencial que esteja claro a concepção teórica do SE para que não ocorra conflitos entre a atuação do professor e o uso do software pelo aluno, criando dificuldades para entender o que esta sendo proposto, porque as teorias de aprendizagem refletem visões diferentes de como ocorre a aprendizagem.

\section{Critérios elaborados a partir da pesquisa realizada nos laboratórios municipais de Lajeado}

A Secretaria de Educação de Lajeado preocupa-se com a inclusão digital faz quatorze anos. Em 1995 foi montado o primeiro laboratório de informática que funcionava em uma sala no centro da cidade. A meta era atender prioritariamente os alunos das dezoito escolas municipais de ensino fundamental, mas grupos de professores também tiveram oportunidade de serem beneficiados.

O objetivo das aulas era capacitar alunos e professores para a utilização do computador e seus principais recursos, como por exemplo, a editoração de textos, de desenhos e de cálculos. Cada escola tinha um horário semanal no qual os alunos, preferencialmente de $7^{\mathrm{a}}$ e $8^{\mathrm{a}}$ série, participavam das oficinas de informática. Justificava-se esta faixa etária tendo em vista que o alunado provinha de classes sócias menos favorecidas economicamente e, portanto, na impossibilidade de atendermos a todos já que o universo de alunos no ensino fundamental atingia a casa dos 5 mil, atender esta faixa etária garantiria, em parte, que, ao chegarem no ensino médio, pudessem ter assegurado um bom conhecimento na área. No entanto, como a proposta da Secretaria de Educação é instalar um laboratório de informática em cada escola, todos os alunos, em curto ou médio prazo, poderão ter acesso a todos esses recursos. Em 2003, foi inaugurado mais um laboratório, este com acesso a Internet, no qual os alunos e professores podiam agendar um horário para realizar pesquisas. Em 2005, a primeira escola recebe um laboratório de informática e em 2006, a segunda. Em 2007, mais três laboratórios foram adquiridos. Atualmente treze escolas possuem seus próprios laboratórios de informática. A proposta dos laboratórios de informática nas escolas é envolver todas as disciplinas dentro de uma perspectiva transdisciplinar, explorando as múltiplas abordagens e formas de apresentação dentro deste novo paradigma, sempre com a coordenação do professor de informática que é o responsável pelo laboratório. No entanto, após a 
compra do hardware e a montagem dos laboratórios, surgiu a preocupação com a aquisição do software. Este produto deve enriquecer a prática pedagógica dos professores e auxiliar o aluno a ser autor do seu processo de aprendizagem.

A avaliação dos softwares educacionais é necessária e urgente para que as escolas adquiram produtos de qualidade. Como muitos autores ressaltam, é muito importante o professor fazer parte da equipe avaliadora. Como afirma Oliveira (2001), é importante que cada escola proceda à avaliação do software, tendo em vista a apreciação de seus professores, no que se refere à adequabilidade do uso desse instrumento como ferramenta de apoio ao seu trabalho educacional e considerando o seu próprio projeto pedagógico. Portanto, é necessária a participação do professor, na avaliação do software educacional.

Um segundo motivo para envolver o professor no processo de avaliação é que ao discutir e elaborar critérios que caracterizam um software educativo pode significar uma orientação no planejamento e na elaboração de projetos pedagógicos que envolvam as tecnologias, para que seu uso possa ser melhor aproveitado.

Com estes propósitos foram enviados questionários para professores que atuam nas séries iniciais do ensino fundamental $\left(1^{\circ}\right.$ ao $4^{\circ}$ ano) de três escolas e dos laboratórios de informática da rede municipal de Lajeado.

O questionário foi elaborado com base nos estudos dos autores Rocha (2001), Oliveira (2001) e Pressman (1995), o qual pretende identificar as características que um software educacional precisa apresentar na visão dos professores. Ele foi dividido em duas partes.

A primeira parte tem como meta identificar a formação profissional, a faixa etária e o tempo de magistério e, desta forma, conhecer o perfil do professor. A segunda parte consiste no levantamento de tipos de programas e das suas características para ser considerado apropriado para o uso nas escolas.

No levantamento dos dados da primeira parte do questionário, conclui-se que a formação profissional dos professores que o responderam é de $50 \%$ com curso normal e $50 \%$ com curso superior, a faixa etária varia entre 20 e 45 anos e $90 \%$ possuem mais de 6 anos de magistério.

Na segunda parte, observa-se que $20 \%$ dos professores que devolveram o questionário apresentam dificuldades ou falta de conhecimento na área da informática, pois não responderam a nenhuma questão. Uma das professoras escreveu "Não conheço nenhum programa educacional, mas sei que é de fundamental importância se trabalhar com estes programas, tendo em vista o avanço na tecnologia e o grande interesse que o aluno tem pela informática. Gostaria até de fazer um curso sobre este assunto".

Este dado obtido aproxima-se da afirmação feita por Oliveira (2001), ainda que já exista um certo nível de informatização das escolas, os educadores parecem perplexos em relação à melhor forma de se utilizar o SE no processo de ensino-aprendizagem.

O objetivo da primeira questão é fazer um levantamento de softwares educacionais que são conhecidos pelos professores; no entanto, a maioria não respondeu. Foram citados o Super Logo, Educativa Expoente Alfabetização, Xerife com x. 
Constata-se, através das respostas, que os professores que conhecem o SuperLogo, preocupam-se com os critérios pedagógicos e de investimentos, considerando-os mais importantes que o layout de tela que no Logo é simples. Na linguagem Logo o mais importante é a investigação, o processo exploratório ao qual é levado o aluno. As justificativas dos professores para a sua escolha são as seguintes:

O SuperLogo, um software desenvolvido baseado em uma linguagem de programação que é do alcance dos iniciantes na área da programação, alunos do ensino fundamental. Onde eu atuo sempre terá esse software, pois ele é free, que é outra grande vantagem.

Conheço e gosto muito de usar o Super Logo. É um software que, aparentemente pode não ser muito atrativo, porém tem um grande poder de desenvolver o raciocínio lógico-matemático do aluno, se for bem aproveitado. É interessante adquiri-lo porque os alunos passam horas em frente dele pensando que estão brincando, mas desenvolvem inúmeras habilidades. Não só é interessante adquiri-lo como é necessário, pois não tem custo algum e está disponível para download.

O outro professor está mais preocupado com os critérios de layout de tela e de registros, mas também se refere à importância pedagógica fazendo referência ao conteúdo trabalhado. A sua justificativa é a seguinte: "Educativo Expoente Alfabetização. Permite os registros do professor. Atrativo para os alunos. Trabalha dificuldades ortográficas e até mesmo lateralidade (para menores). E Xerife com "x". Este permite trabalho com narrativa e ortografia"

A segunda e a terceira questão abordam especificamente às características que um software deve ter para ser considerado educacional e a partir deste levantamento é possível determinar os critérios necessários para a avaliação do programa.

Faz parte do trabalho do professor analisar o material que o aluno utilizará em aula, por isso uma das respostas merece um destaque especial, pois a professora escreveu:

Analisaria-o como analiso todo o material didático que adquiro: linguagem apropriada, jogos e atividades atrativas, diversificadas, desafiadoras, que valorizam positivamente os usuários dando-lhes reforços positivos.

Constatou-se que $98 \%$ dos professores se preocupam em relação aos aspectos pedagógicos. Para eles, as atividades propostas pelo software educacional devem ser desafiadoras e diversificadas, os objetivos claros e conteúdos coerentes e significativos, adequados a faixa etária e ao nível de aprendizagem do aluno. Como se constata nas seguintes respostas

Creio que hoje os "softwares" deveriam conter atividades desafiadoras, que façam os nossos alunos pensarem. Atividades que envolvam uma linguagem apropriada como charadas, cruzadinhas, jogo dos 7 erros, produção de histórias e outros, que não façam o nosso aluno somente pintar de acordo com as cores disponíveis.

Se realmente faz o aluno construir o conhecimento, e não traga tudo pronto. Conteúdo coerente.

Em relação ao modelo de aprendizagem que é privilegiado, os professores procuram um software que auxilie na construção do conhecimento, fazendo o aluno pensar e criar, 
instigando a curiosidade e o interesse, tendo como base o construtivismo. Como se pode constatar na seguinte resposta:

O software educacional representa um poderoso recurso ou ferramenta educacional a ser utilizado com os alunos em seu processo de aprendizagem ao permitir que os mesmos criem, comuniquem-se e resolvam problemas. Enfatizo aqui a questão do "aprender fazer, fazendo". Os alunos devem ser sujeitos ativos e não meros receptores de informações. O software funcionará efetivamente como instrumento no processo de ensino e aprendizagem se for inserido num contexto de atividades que desafiem o grupo em seu crescimento. Espera-se que os alunos construam o conhecimento. Um software educacional deveria promover a interação e a articulação entre os conhecimentos das diversas áreas. Falo aqui sobre a questão da interdisciplinaridade. Há a possibilidade de que, a partir de uma atividade, abram-se as portas para uma série de outras que podem ser solicitadas ou sugeridas.

A necessidade da linguagem ser apropriada aos alunos, que é um critério da facilidade de uso do software, foi abordado por $2 \%$ dos professores. É evidente que para o aluno aproveitar o máximo do software, o vocabulário e as estruturas das frases da interface devem ser adequados ao público-alvo.

A quarta questão se refere à abordagem do erro do aluno durante a execução das atividades propostas pelo software. A presença de erros na resposta do aluno deve dar oportunidade a novas informações sobre o conteúdo trabalhado, para melhor compreensão do assunto e auxiliar na construção do conhecimento. Para 55,5\% dos professores o erro deve ser construtivo, o aluno deve ser indagado e desafiado a tentar novamente.

O erro deve ser abordado como uma tentativa e receber a interferência do professor para a partir deste erro crescer superando sua hipótese.

[...] sempre de forma construtiva, ou seja, posso construir a forma correta mesmo depois do "erro".

$\mathrm{O}$ erro deve ser abordado da mesma forma como em sala de aula para $22 \%$ dos professores, consideraram o erro como algo natural $5,5 \%$ e $16,6 \%$ pensam que com o erro a criança deve ser incentivada e entusiasmada a tentar novamente, mas que não fique com vergonha.

O erro deve ser abordado como um novo desafio para que o aluno vença, também como motivação para que jamais desista de aprender.

De maneira que a criança se incentive e entusiasme a continuar e a evoluir e não fique com vergonha.

O trabalho com o SE não descarta a presença do professor que é fundamental para ajudar e questionar o aluno na superação das dificuldades encontradas. Por ser tão importante este critério, a quinta pergunta aos professores se refere as suas atribuições durante o uso do computador pelos alunos. Os professores responderam que seu papel é de orientador para 25\%; mediador para 12\%; um aprendiz para 16,6\%; um acompanhante para 8,3\%; auxiliar e ajudar quando necessário para $25 \%$; um incentivador para $8,3 \%$ e um interventor para $4,1 \%$. Constata-se que a maioria dos professores possui uma concepção construtivista na qual é fundamental uma mediação permanente do professor, que é o profissional capaz de realizar os ajustes necessários 
entre o conteúdo a ser aprendido e a atividade cognitiva daquele que aprende. (Oliveira, 2001)

Um dos professores respondeu:

Cabe ao professor incentivar, objetivar e direcionar o uso do software educacional como ferramenta para a construção do conhecimento. Ressalto o fundamental papel do professor mediador e facilitador do processo de ensino aprendizagem dos seus alunos, proporcionando um ambiente capaz de estabelecer conexões individuais e coletivas. $\mathrm{O}$ professor procura acompanhar o processo de criação e descoberta de seus alunos.

Outro professor considerou o seu papel um mediador, mas que não seja um facilitador. Este é um aspecto importante, pois podem existir dois tipos de mediadores: o facilitador que apenas responde a dúvida do aluno e o complicador que questiona e faz o aluno pensar.

O professor deve ser o mediador do processo de construção do conhecimento na relação aluno-computador. Jamais deve ser um facilitador, mas sim, um complicador, que faça o aluno refletir sobre suas ações.

Verificou-se que a preocupação principal dos professores é com os critérios pedagógicos. Como afirma Rocha (2001), características de interface mudam muito de acordo com a categoria e/ou abordagem pedagógica de um software (...) um software que tem como fundamentação teórica-pedagógica o construtivismo, um feedback do tipo certo e errado, gera uma inconsistência que compromete a qualidade. Portanto, o software deve permitir a identificação da concepção teórica que ele privilegia, ser adequado a um dado contexto educacional ou disciplina específica, atender aos objetivos pedagógicos e aos conteúdos, ter claro o papel do professor e o tratamento do erro ser coerente com a proposta teórica.

No entanto, também, é necessário o cuidado em relação aos seguintes aspectos citados por Rocha (2001):

- características pedagógicas: atributos que evidenciam a conveniência e a viabilidade de uso do software em situações educacionais.

- facilidade de uso: atributos que evidenciam a facilidade de uso do software.

- características da interface: atributos que evidenciam a presença de recursos e meios que facilitam a interação do usuário com o software.

- adaptabilidade: atributos que evidenciam a capacidade do software adaptar-se às necessidades e preferências do usuário e ao ambiente educacional selecionado.

- documentação: atributos que evidenciam que a documentação para instalação e utilização do software está completa, é consistente, legível, e organizada.

- portabilidade: atributos que evidenciam a adequação do software aos equipamentos onde serão instalados.

- retorno do investimento: atributos que evidenciam a adequação do investimento na aquisição do software.

Além desses aspectos, devem ser considerados critérios como: preço acessível, disponibilidade no mercado, possibilidade de obtenção de cópias, convênios e análise de versões demonstrativas. 


\section{Considerações finais}

Atualmente presencia-se uma fase de transição entre o professor tradicional e a geração digital, exigindo, além de uma mudança de paradigma, também uma nova postura do professor. Frente a essa nova realidade o professor incorpora o uso das novas tecnologias, julgando e analisando-as criticamente. Como afirma Perrenoud (2000), formar para as novas tecnologias é formar o julgamento, os senso crítico, o pensamento hipotético e dedutivo, as faculdades de observação e de pesquisa, a imaginação, a capacidade de memorizar e classificar, a leitura e a análise de textos e de imagens, a representação de redes, de procedimentos e de estratégias de comunicação. Portanto, para apropriar-se destas novas tecnologias, é preciso avaliar e analisar, principalmente, o software que será utilizado.

\section{Referências}

CAMPOS, Gilda Helena de. A qualidade em Software Educacional. http://www.cciencia.ufrj.br/publicacoes/artigos.htm

GIRAFFA, Lucia Maria Martins. A classificação dos Softwares Educacionais: nós necessitamos mesmo de uma taxonomia?1999. Artigo publicado em: http://www.edukbr.com.br/portal.asp

OLIVEIRA, Celina Couto de; COSTA, José Wilson da; MOREIRA, Mercia. Ambientes informatizados de aprendizagem: Produção e avaliação de software educativo. Campinas: Papirus, 2001.

PERENOUD, Philippe. Dez novas competências para ensinar. Porto Alegre: Artes Médicas Sul, 2000.

PRESSMAN, Roger S. Engenharia de software. São Paulo: Makron Books, 1995.

ROCHA, Ana Regina Cavalcanti da. Qualidade de Software. São Paulo: Prentice Hall, 2001.

SANCHO, Juana M. (Org). Para uma Tecnologia Educacional. Porto Alegre: ArtMed,1998.

VALENTE, José Armando (org.). O computador na sociedade do conhecimento. Campinas: UNICAMP/NIES, 1999.

VIEIRA, Fábia Magali Santos. Avaliação de Software Educativo: Reflexões para uma análise criteriosa. Disponível em: http://www.nuted.edu.ufrgs.br/biblioteca/public_html/9/30/index.html Acesso em: 10/06/06.

WEBER, Kival Chaves. Qualidade e produtividade em software: Termo de referência do subprograma setorial da qualidade e produtividade em software, do Programa Brasileiro da Qualidade e Produtividade. São Paulo: Makron Books, 1997. 